
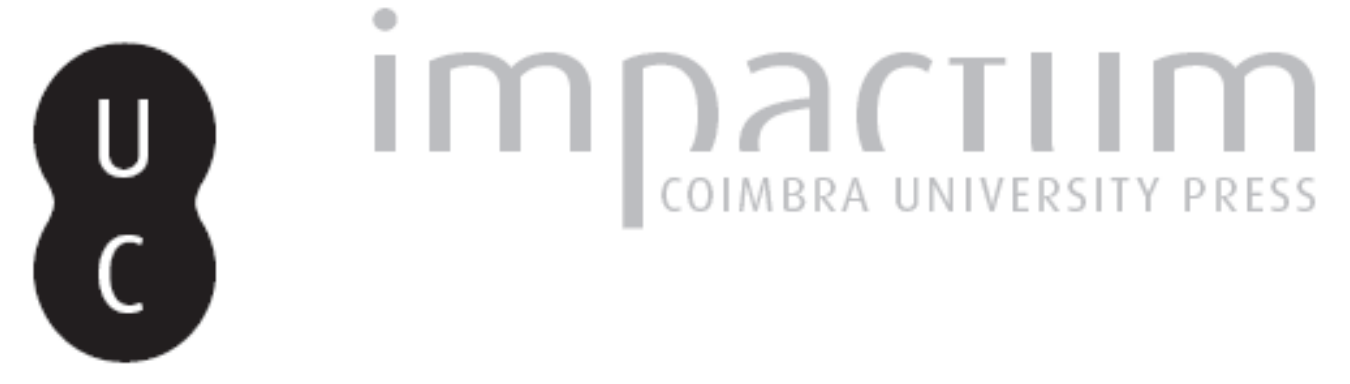

\title{
Entre palácios e moagens
}

\section{Autor(es): Olaio, António}

Publicado por: Editorial do Departamento de Arquitectura

URL persistente:

URI:http://hdl.handle.net/10316.2/37407

DOI:

DOI:http://dx.doi.org/10.14195/0874-6168_1_2

Accessed : $\quad$ 26-Apr-2023 16:02:27

A navegação consulta e descarregamento dos títulos inseridos nas Bibliotecas Digitais UC Digitalis, UC Pombalina e UC Impactum, pressupõem a aceitação plena e sem reservas dos Termos e Condições de Uso destas Bibliotecas Digitais, disponíveis em https://digitalis.uc.pt/pt-pt/termos.

Conforme exposto nos referidos Termos e Condições de Uso, o descarregamento de títulos de acesso restrito requer uma licença válida de autorização devendo o utilizador aceder ao(s) documento(s) a partir de um endereço de IP da instituição detentora da supramencionada licença.

Ao utilizador é apenas permitido o descarregamento para uso pessoal, pelo que o emprego do(s) título(s) descarregado(s) para outro fim, designadamente comercial, carece de autorização do respetivo autor ou editor da obra.

Na medida em que todas as obras da UC Digitalis se encontram protegidas pelo Código do Direito de Autor e Direitos Conexos e demais legislação aplicável, toda a cópia, parcial ou total, deste documento, nos casos em que é legalmente admitida, deverá conter ou fazer-se acompanhar por este aviso.

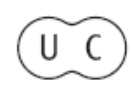




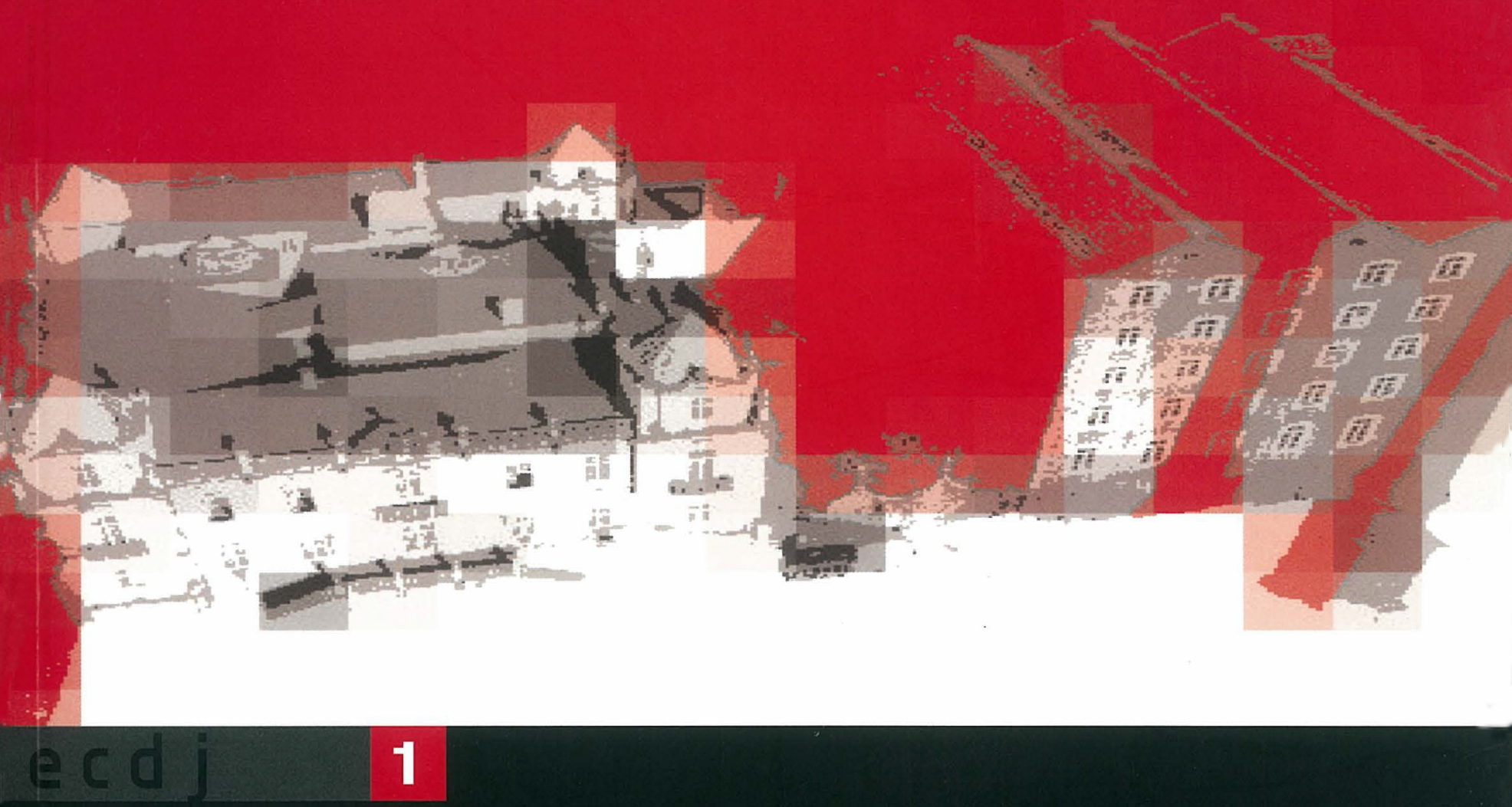

fctuc / departamento de arquitectura

\section{a polémica do Freixo Fernando Távora} alexandre alves costa | antónio olaio joão paulo rapagão | jorge figueira josé antónio bandeirinha

(2) 


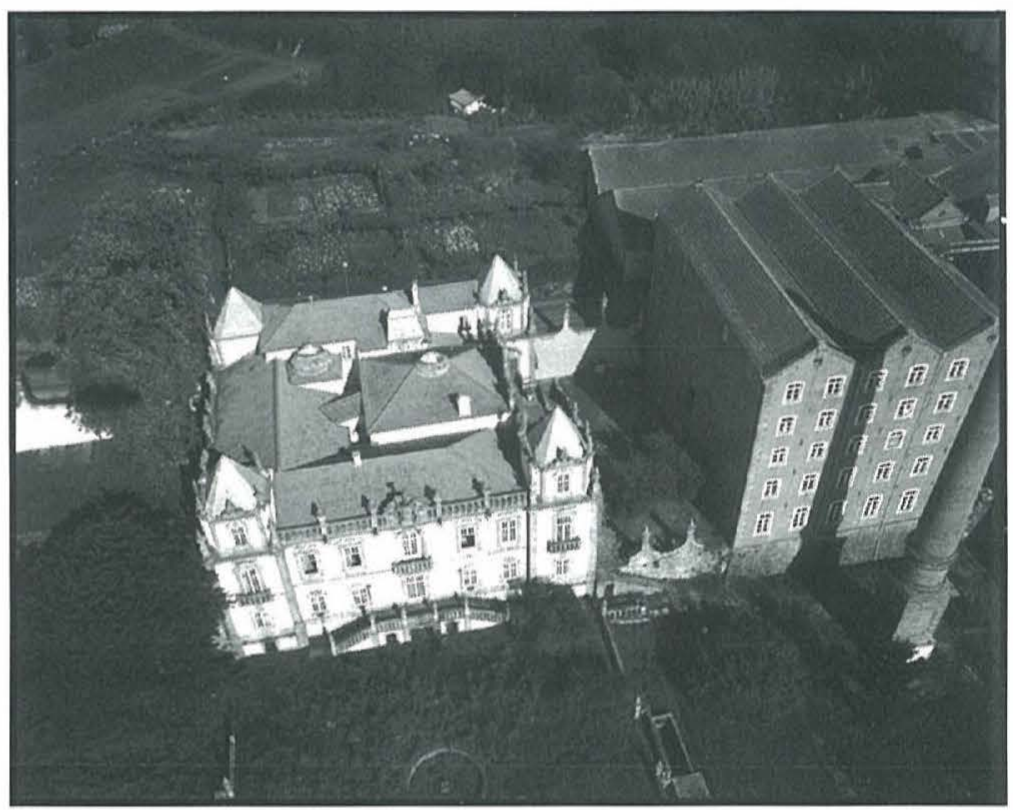


Em Outubro de 97, a Fundação de Serralves realizou a exposição antológica de James Lee Byars: The Palace of perfect.

> James Lee Byars, na sua procura da ideia de perfeição, encontrou na Casa de Serralves a materialização de um espaço ideal para a sua obra, chegando a considerar aquela casa como sendo o próprio Palácio da Perfeição.

> Confesso que, inicialmente, não pude deixar de considerar a sua obra extremamente irritante.

> A eleição dos objectos que associou à ideia de perfeição, dos quais posso destacar uma lindíssima cadeira veneziana (suponho que do séc. XV ou XVI), a frequente utilização do dourado e a procura dos sólidos perfeitos, levou-me a crer que esta ideia de perfeição não deixaria de resultar numa caricatura. 
> Na sua relação entre o dourado e a perfeição, muitas vezes sem considerar a sua adequação, levou-me a crer que o seu carácter simbólico não bastaria até porque uma panela de ferro, por exemplo, como refere Sócrates, ou Platão através de Sócrates, no Hípias Maior, não poderá deixar de ser considerada bela, na medida em que serve perfeitamente a sua função. E, quanto a mim, por isso mesmo, bem mais bela do que uma panela de ouro.

> O encarar dos sólidos perfeitos como imagem de perfeição, levou-me a crer que estaria a confundir perfeição com uma mera racionalização das formas.

> The chair of transformation, título da cadeira veneziana exposta, e coerente com o próprio carácter orgânico da sua forma, parecia contradizer a ideia de perfeito. A cadeira era indiscutivelmente bela, mas a sua beleza, como Byars, com este título, teve de admitir, advinha da organicidade da sua forma, deste seu carácter de forma transitória, quase animal, e, assim, por contrariar a fixidez de uma forma absoluta, longe de qualquer coincidência da ideia de beleza com a ideia de perfeição.

> De facto, se encararmos a obra de James Lee Byars, como uma verdadeira procura da perfeição, esta não poderia deixar de ser considerada como sendo de uma demagógica arrogância.

> Mas acredito que James Lee Byars, mais do que procurar, de facto, a ideia de perfeição, encontrou formas de comunicar, metaforicamente, essa procura, valorizando mais a facilidade de comunicação que o rigor (o que, no que diz respeito à perfeição, deveria ser impossível de conseguir). E como as obras de arte podem ser sobretudo o efeito que produzem (o que, acredito, teria James Lee Byars estrategicamente previsto), tenho de admitir que esta exposição, neste sentido, talvez tenha sido uma das mais interessantes, senão a mais interessante exposição que vi.

> Numa época em que se convencionou que a vanguarda se teria de afirmar pela negação, esta obra, não se limitando só à ideia de Belo, mas ousando afirmar uma intenção de perfeição, adquire um extraordinário efeito que não se limita ao provocatório, recolocando questões e conceitos que teriam, quanto a mim contra natura, sido banidas do próprio léxico da reflexão estética actual. 
> A contemporaneidade não é ou não deveria ser, uma espécie de fatalidade!

> De facto, a contemporaneidade, nunca deverá ser, por si, uma questão importante, porque pela sua própria natureza de estar presente, nunca precisa de ser preservada.

> A única preocupação que poderíamos ter seria a possibilidade de não sermos contemporâneos dos nossos amigos, o que seria um evidente disparate.

> A preservação de tudo, que leva ao próprio exagero de certas atitudes da chamada arqueologia industrial, chega ao ponto de não se saber os limites do que deve ser preservado.

> Quanto tempo terá de ter uma coisa para que mereça a preservação? Esta atitude de preservação compulsiva, no limite levará a que tenhamos de nos constantemente ocupar da preservação do próprio presente, e, mesmo, da preservação do próprio instante presente.

> Esta ideia de contemporaneidade como museu é algo, que, de facto poderá ser, mesmo preocupante.

> Qualquer projecto de intervenção numa preexistência seria impossível, se não estivesse já concretizado. Mas se já o estivesse, o que se tornaria premente seria, a todo o custo cuidar da sua preservação.

A questão que se deverá colocar, se conseguirmos resistir a esta patologia da realidade como museu, no caso do projecto de Fernando Távora para a recuperação do Palácio do Freixo, será esta: O que será melhor e, permitam-me a ousadia, mais belo? A preservação da situação actual do edifício contaminado pela construção das Moagens Harmonia, ou a recuperação da relação original com o Palácio?

> De facto, creio que não se poderá discutir esta questão sem a recuperação da ideia de beleza.

> A vivência do presente, cria-nos o gosto pela contaminação das formas, por uma realidade em constante transformação, o que pode alimentar a própria criatividade.

> Mas quando, a qualquer custo, é, por si só, preservada a contaminação, mesmo só pela ideia de preservação, estamos, sobretudo a limitar toda e qualquer criatividade.

> Foi a criatividade de Nasoni que fez o Palácio do Freixo não foi a criatividade que gerou a contaminação do Palácio do Freixo pelas 
Moagens Harmonia, e, infelizmente, nem sequer o acaso, mas sim, e não poderemos deixar de o admitir, o completo e insensivel desrespeito pela qualidade arquitectónica. E, aqui, o próprio nome Harmonia, não deixa de surgir como uma espécie de acidental ironia.

> De facto, a intenção de preservar o Palácio e as Moagens tal como estão, mais não será do que uma evidente premiação de um acto esteticamente criminoso acreditando que só o não será pelo mero facto de ser passado.

> Não podemos, contudo negar que o hábito de ver o palácio tal como está, faz criar raízes entre o edifício das moagens e o palácio, chegando a esteticizar-se uma relação que inicialmente não deveria ter deixado de ser conflituosa.

> Também não será difícil teorizar esta sensação de harmonização entre edifícios com caracteres tão diferentes, até porque a sua diferença abre caminho para o, tão aliciante e apreciado jogo da dialética.

> Mas o que não podemos deixar de ter em conta é o facto desta atitude também poder ser a mais fácil, e a mais popular, no povo ou nas elites culturais, e, por isso mesmo, a mais impunemente demagógica, até porque será a atitude que levará a não fazer nada. E, na ausência de fortes conviç̧ões, é muito mais cómodo optar pelo conservadorismo, no seu sentido mais estrito.

> Neste sentido, temos de admitir que a atitude de Fernando Távora é extremamente corajosa porque é, de facto uma atitude.

> E Fernando Távora, com este seu projecto, recolocando a questão da qualidade estética, e, acredito, a própria ideia de beleza, revela o projecto arquitectónico como intervenção no próprio campo das ideias. E não será esta postura a que caracteriza a arte contemporânea e que é a sua própria força motriz?

> Atitude ainda mais ousada por não o parecer de todo, nas expectativas de que a arte contemporânea crie rupturas, e não, de forma alguma, recuperações.

> Ter uma atitude no seio da arte contemporânea que não faça qualquer questão em parecer contemporânea, dá, inclusivamente maior credibilidade à própria prática artística, enquanto resultado da inteligência e não de qualquer exercício de relações públicas.

> Numa realidade em que a contemporaneidade é um vício, repensar a estética, voltando a admitir a possibilidade de valores absolutos, e 
colocando a inteligência acima de quaisquer preconceitos de modernidade, talvez seja a atitude que mais nos falta.

> Este projecto de recuperação do Palácio do Freixo, que, a bem da arte, deveremos esperar ver concretizado, desde já tem a enorme qualidade de potenciar uma reavaliação dos valores estéticos predominantes, ou, melhor, discernir ou pôr em questão o que se poderá entender por valores estéticos, que, podendo ser sempre relativizados, não deverão deixar de ser objecto de uma hierarquia.

> Ninguém negará a importância da preservação do café Magestic, mas se tivéssemos de escolher entre o café Magestic e a Torre dos Clérigos, acredito que, unanimemente (incluindo o proprietário do café Magestic), escolheriamos a Torre dos Clérigos.

> Para quem disser que fica tão bem o Palácio do Freixo com as Moagens Harmonia, bom será que veja se está perante uma mera questão de gosto, ou se de facto a inteligência terá alguma coisa a ver com isso.

> Não é por uma questão de gosto que Fernando Távora propõe esta recuperação do Palácio do Freixo, mas sim por uma questão de desenho.

> Se este projecto for concretizado, para além de tudo será uma forma de reconhecer a própria validade da arquitectura.

> Esperemos que a patine do tempo não venha, por exemplo, a tornar belíssimo qualquer centro comercial da Sonae nos hoje tão celebrados edifícios de Álvaro Siza, da Faculdade de Arquitectura do Porto.

> De qualquer forma, Fernando Távora não deixa de reconhecer qualidade no edifício das moagens, propondo, inclusivamente a sua reconstrução noutro local, e desta forma o resgata da situação de ter resultado de uma completa insensibilidade em relação ao Palácio do Freixo.

> Como Nasoni não está vivo, a atitude de Fernando Távora na procura de recuperação do seu projecto, no mínimo deverá ser considerada na sua indiscutível dimensão ética. 